\title{
TYPOLOGY AND REGIONALIZATION OF CONTEMPORARY LANDSCAPE DEVELOPMENT PROCESSES IN POLAND
}

Research in the area of dynamic geomorphology has been developing in Poland like in other countries. This results from both cognitive interest and practical needs. The research is aimed at a more detailed presentation of the studied problems and at a shift from qualitative results to quantitative results and ascertaining an interdependence of various processes as well as forecasting a further evolution of the landscape in result of more general changes in specific morphoclimatic zones. Landscape transformations can be secular or can occur within yearly climatic cycles. Knowledge of secular changes makes it possible to forecast trends and directions of landscape development. Following yearly processes makes it possible to present the present intensity of processes and their distribution. Seasonal morphodynamic processes can sometimes be catastrophic for specific localities. They can be an effect of natural factors or of man's activity. The research on landscape dynamics has been concentrating on studying individual processes or a sum of them in small areas.

Nevertheless, in order to upgrade the value of the results, it is necessary to make a quantitative evaluation of contemporary denudation within closed systems of matter circulation, that is to aim at systemic approaches as river basins are treated as systems. A quantitative dimension of phenomena in a systemic approach is a necessary factor to make it more scientific and more practical. Studies on matter circulation in systems occurring in contemporary morphological processes show their mutual functional and dynamic interdependence. One should remember, however, that co-occurrence does not necessarily mean interdependence. Processes must not be treated as isolated objects since they make up interrelated systems.

In Poland various institutions undertake studies in the area of dynamic geomorphology. Studies are conducted on efficiency of specific slope processes, total rock mass is calculated that was removed from the slope in effect of various processes, including chemical, gravitational, eolithic, sliding, fluvial as well as the impact of man's economic activity on changes in the landscape. So far most of the studies have been made on surface and rill wash. 
In Poland there has been a tendency towards narrow research specialization with respect to specific processes. They are worth as much as qualitative, and sometimes quantitative, analyses. Now it is necessary to approach problems as a whole to show interdependence between processes as well as between processes and various elements of the geographical environment. According to today's knowledge, it is clear that natural conditions are very important in the genesis, intensity and course of processes, e.g. for wash processes forests slow it down, crops, particularly root crops, intensify the process, slope and permeability of the soil influence water run-off or its infiltration.

All scientists agree that it is necessary to know the background, composed of genesis of the landscape and its morphometric features, climatic conditions, lithological features and vegetation cover. Knowledge of contemporary morphodynamic processes and their efficiency is a basis to discover trends in a further evolution of the landscape. The situation in research on contemporary processes is propaedeutical, nevertheless there are ways to raise the rank of those studies that are of both cognitive and pactical value.

This postulate should be implemented through systemic studies within river basins which can be looked upon as whole and within which there are functional relations between specific morphodynamic processes. The relations are characteristic for systems and thus it is possible to move from analytical studies to synthetic approach. Analytical studies - qualitative, reveal a general development trend whereas quantitative studies, by the dimension of phenomena, reveal the rank of the events and are very important for man's economic activity. In the the south-east of Poland, where group studies on dynamic geomorphology were undertaken within the farmework of an interministerial program "Changes in Poland's geographical environment", the following were recognized as major landscape development processes: chemical denudation, chemical changes in soil cover, surface wash (dispersed and concentrated), gravitational processes (sliding), fluvial and eolithic processes.

The research had two objectives: development of a methodological base and presentation of a spatial structure of trends in phenomena modelling the landscape of the analysed area. The following theories were used to develop methodological base:

- contemporary morphogenetic phenomena result from paleomorphogenesis as their occurrence and efficiency depend largely on geological structure and landscape formed in the past;

- apart from the "ingerited" landscape of the Earth, spatial differentiation of activity of climatic factors and manner of man's activity if geographical space are decisive for the character of phenomena characteristic of the contemporary link of the morphogenetic system;

- the third element in the studied system, that is morphogenetic forecast, can be determined only indirectly by studying the functionining of the previous elements. 
It was assumed that Poland's landscape, as inherited after the previous morphogenetic epochs, is currently transformed by two categories of processes, differing in their nature of action. The present stage of landscape evolution can be viewed as causalities, characteristic on the one hand of chemical system, and on the other of the physical system of landscape modelling.

Within the system of chemical denudation, the following can be distinguished: a soil subsystem, represented by processes of leaching and souring, and a rock subsystem, represented by karstic phenomena.

However, a presentation of a synthesis of studies on the process of chemical denudation in Poland requires a common measure, reflecting the effects of impact of the two mentioned subsystems. Quantity of matter transported in the form of solutions, expressed in $t / \mathrm{km}^{2} /$ year, was taken as a measure presenting the spatial differentiation of the value of chemical denudation balance which always is negative.

Within the system of physical denudation there are the following:

- surface-slope subsystem, represented by proceses of dispersed and concentrated wash processes and gravitational mass movements;

- subsystem of valley bottoms and hollows, represented by manifestations of accumulation activity of the wash processes and gravitational mass movments.

Biogenic-type processes present a classification problem, however one may assume that the final morphological effect is a result of chemical and physical phenomena, active within the subsystem of valley bottoms and hollows.

The contents of a synthetic map seemingly excludes morphological effects of man's activity, apart from its extreme manifestations. It was also recognized that almost all processes modelling Poland's landscape are largely conditioned by the morphogenetic factor.

When analysing the denudation balance of the listed physical subsystems of modelling the Earth's surface one can state that for surface-slope areas it is almost always negative whereas for valley bottoms and hollows it can be negative, balanced and positive.

Bottoms of river valleys and hollows were distinguished and for those a dominating type of balance was determined, differentiated in relative values. The other areas were termed as inter-valley. For those the dominating type of balance was determined as a resultant of balances occurring within the subsystems existing in them. It was also diferentiated in relative values.

A synthetic picture of trends in physical denudation in Poland was presented with spatial typological units, characterized by type and category of matter balance. And a synthetic picture of trends in chemical denudation was obtained with isolines, indicating the volume of dissolved substances transported from a given area. 
TYPES OF DENUDATION BALANCE

Poland's landscape is subjects to constant changes in effect of various processes. The processes work in hierarchic dynamic systems of various complexity. Each system is composed of a group of various interrelated elements and is characterized by a different type of denudation balance. Among the largest systems there are river-basins composing unique natural open systems. The measure of denudation in those areas is volume and index of treansportation of floated and dissolved matter per $1 \mathrm{~km}^{2}$ of surface area.

Total quantitative results for large river-basins provide only a general characteristics since they do not provide information of either dynamics of landscape development or of special differentiation and share of individual morphogenetic processes in the modelling. Each basin is composed

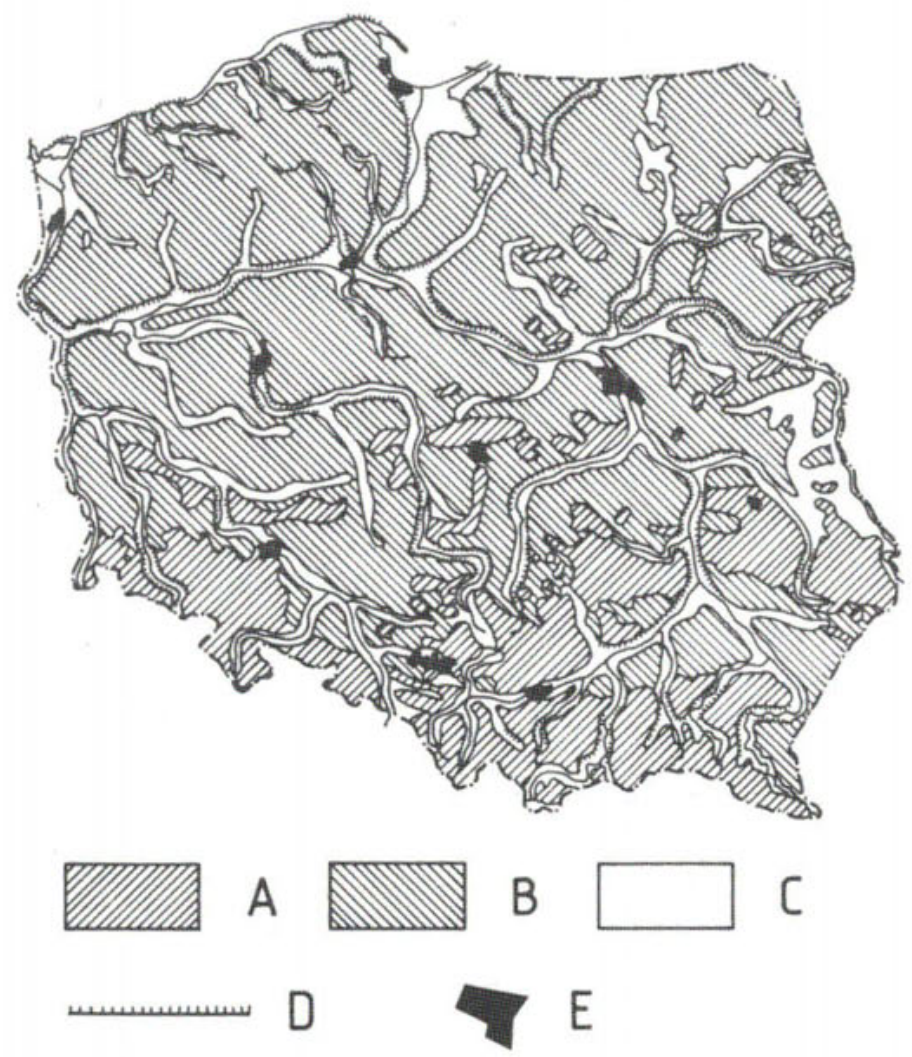

Fig. 1. Types of modelling. A - degradation type, B - type with equilibrium of degradation and agradation, $\mathrm{C}$ - agradation type, $\mathrm{D}-$ scarps and cliffs, $\mathrm{E}-$ towns 
of two basic subsystems: slopes and valley bottoms. Generally on slopes discharge (degradation) takes place whereas deposition (agradation) occurs in valley bottoms. The material is usually transported on short distances. Some of the material is transported down the river. Hollows within the basin make up separate systems. Deposits transported from higher areas (mountains, uplands) are accumulated there.

Extensive plains, particularly in central Poland, have a stable denudation balance. Due to small slope and insignificant delevelling, mostly dissolved rock material is transported to rivers. Less frequently it is suspended matter.

Lake-basins and hollows without issue constitute separate closed systems of various size. They are also local denudation bases, both for slopes and small valleys.

Eolithic processes have a major role in landscape modelling, particularly at the seaside as well as in the valleys of big rivers, in the mountains above the upper forests limit as well as in agricultural and industrial areas.

\section{TYPES OF MODELLING}

When distinguishing the types of balance of landscape modelling, the following were considered: type of denudation balance (excess of denudation, agradation or equilibrium), dominating factor and process as well as intensity of phenomena. Thus three types of landscape modelling were distinguished (Fig. 1) and within those five subtypes.

\section{A. Degradation type}

It covers areas with different intensity of processes, all of which have an excess of transport away from them. Areas with a very high intensity of processes (mechanical denudation index in the Carpathians $97,9 \mathrm{t} / \mathrm{km}^{2} /$ year, chemical denudation index $36,3-54,3 \mathrm{t} / \mathrm{km}^{2} /$ year, on loess uplands over $61,3 \mathrm{t} / \mathrm{km}^{2} /$ year) with prevalence of washing, leaching, suffosion and eolian processes, characterized with short distance transportation. Some material is deposited at the feet of the slopes and in bottoms of smaller valleys. Areas with high intensity of processes (mechanical denudation index $30-50 \mathrm{t} / \mathrm{km}^{2} /$ year, chemical denudation index $20,5-54,3 \mathrm{t} / \mathrm{km}^{2} /$ year) occur in uplands constructed mostly of silicate rock. They are modelers largely by leaching, washing, gravitational and eolian processes.

Degradation areas with low intensity of processes cover uplands built from coal rock with prevalance of leaching (mechanical denudation index $9 \mathrm{t} / \mathrm{km}^{2} /$ year, chemical denudation index $54,3-61,3 \mathrm{t} / \mathrm{km}^{2} /$ year) as well inselbergs of moraines, kames and eskers (mechanical denudation index about $1,5 \mathrm{t} / \mathrm{km}^{2} /$ year, chemical denudation index $8,3-20,5 \mathrm{t} / \mathrm{km}^{2} /$ year) model led mainly by washing. 
Among degraded areas there are also cliff seasides destroyed in effect of abrasion (0,1-1,3 $\mathrm{m} / \mathrm{year})$ and high erosiondenudation edges with a large share of gravitational processes apart from washing and suffosion.

\section{B. Type woth equilibrium of degradation and agradation}

Areas with a high intensity of processes and limited transport with prevalence of washing, gravitational and cryogenic processes, cover high mountains layers. Some material is deposited at the foot of slopes of highly located watershed glacial valleys. Chemical denudation at the layer of lime peaks reaches $100 \mathrm{t} / \mathrm{km}^{2} /$ year and at the layer of granite peaks it is $15.30 \mathrm{t} / \mathrm{km}^{2} /$ year.

Areas with a modest intensity of processes, modelled mainly by leaching, washing and biogenic processes cover hills of moraines, kames and askers of the young glacial zone. The mechanical denudation index in those areas reaches $5 \mathrm{t}^{\mathrm{km}} /$ year and the chemical denudation index reaches $20,5-41,0$ $\mathrm{t} / \mathrm{km}^{2} /$ year. A large portion of the material is deposited in lakes and hollows without issue.

A weak intensity of processes, mainly leaching, washing and biogenic processes occur on moraine plains of the young glacial zone. The mechanical denudation index is about 3-4 $\mathrm{t} / \mathrm{km}^{2} /$ year and the chemical denudation index is $41,0-61,3 \mathrm{t} / \mathrm{km}^{2} /$ year. Some of the material, similarly to the previous subtype, is deposited in the immediate neighbourhood in lakes and hollows without issue.

Areas with a very weak intensity of processes include old glacial denudation index in those areas is $1,3-1,5 \mathrm{t} / \mathrm{km}^{2} /$ year and the chemical denudation index is $8,0-20,5 \mathrm{t} / \mathrm{km}^{2} /$ year.

\section{Agradation type}

The areas with prevalence of agradation include river valleys and basins where sands and gravel are accumulated, lakes and swamps with prevalance of biogenic processes, sand-bars and sea beaches built up in effect of sea and eolian processes as well as areas with prevalence of anthropogenic agradation which include urban and industrial centres with dumping grounds and mouds.

\section{REGIONAL DIFFERENTIATION OF CONTEMPORARY LANDSCAPE DEVELOPMENT PROCESSES IN POLAND}

In various geomorphological regions, the balance and intensity of processes is different. There is a relation to the type of rock and soil, volume of precipitation, energy of the landscape, tectonic trends and man's interference. The Carpathians are characterized by a high intensity of processes and transportation of material on long distances. In landscape 
modelling sliding processes prevail on Flysch subsoil. Only in the Tatra suspended valleys there is no transport away and in intermountain basins agradation prevails.

In the Sudeten the intensity of processes varies much. The characteristic feature is no sliding.

The Pre-Carpathian valleys and the feet of the Sudeten generally are a zone of agradation, degradation processes have a weak intensity.

In the uplands zone there is a large variety in the type and intensity of processes, from karstic on limestone to washing, suffosion with ravine erosion on loess soil. In those areas there is prevalence of transportation of rock material partly in valley bottoms and partly beyond the uplands.

Old glacial lowlands are characterized by stability and a very weak intensity of processes and an equilibrium between degradation and transit agradation. In young glacial lowlands there is a variety of the type of balance and intensity of processes, though generally there is an equilibrium between degradation on slopes and agradation in numerous lakes and hollows without issue.

Cliff seaside of the Baltic retractes and flat coast is built up in effect of sea processes and transformed by eolithic processes. 
